\title{
Low genetic variability within and among populations of the brooding sponge Rhopaloeides odorabile on the central Great Barrier Reef
}

\author{
S. Whalan ${ }^{1,2, *}$, R. de Nys ${ }^{1,2}$, C. Smith-Keune ${ }^{1}$, B. S. Evans ${ }^{1}$, C. Battershill ${ }^{2,3}$, D. R. Jerry ${ }^{1,2}$ \\ ${ }^{1}$ School of Marine \& Tropical Biology, and ${ }^{2}$ AIMS@JCU Tropical Aquaculture, James Cook University, Townsville, \\ Queensland 4811, Australia \\ ${ }^{3}$ Australian Institute of Marine Science, PMB 3, Townsville, Queensland 4810, Australia
}

\begin{abstract}
The population genetic structure of the brooding sponge Rhopaloeides odorabile (Dictyoceratida) was examined at 3 polymorphic allozyme loci and the partial mitochondrial cytochrome oxidase sub-unit 1 gene (CO1) sequence (528 bp) from multiple sites across the central Great Barrier Reef (GBR), Australia. Distances between sampled sites ranged from a few 100 metres to $140 \mathrm{~km}$. Observed levels of allozyme variation were generally low, and there were only minor differences in allozyme allele frequencies evident between sites. Likewise, levels of polymorphism for mtDNA CO1 were also low, with only 3 haplotypes found at this locus and with 1 of the 3 haplotypes present at all sites with frequencies ranging from 0.55 to 1.00 . There was no obvious partitioning or structuring of the observed allozyme or CO1 genetic variance with spatial positioning of populations and no evidence in this sponge species for genetic differentiation between inner- and mid-reef sites. However, there was evidence against complete genetic panmixia across the central GBR, with 2 pairs of innerreef sites sampled in 2004 genetically differentiated from most other pairwise site comparisons, and both pairs were also different from single sites within a few 100 metres sampled in the previous year. When viewed together, nuclear and mtDNA markers indicate large-scale genetic admixture in this species, although there is some evidence for small, localised, genetic differences between some populations that might be determined by reef-specific hydrodynamics. This pattern is consistent with the endogenous recruitment expected from a brooding species and with dispersal that is infrequent enough to prevent divergence among populations.
\end{abstract}

KEY WORDS: Brooding sponge $\cdot$ Larval dispersal $\cdot$ Genetic variability $\cdot$ Connectivity

\section{INTRODUCTION}

Sponges are a conspicuous taxon within aquatic ecosystems, inhabiting both fresh (Manconi \& Pronzato 2008) and marine biotopes, spanning tropical (Fromont et al. 2006), temperate (Schlacher et al. 2007) and polar zones (Kowalke 2000). Members of this group play important ecological roles (Wulff 2001) within aquatic environments, and several species are also commercially important (Sipkema et al. 2005, Louden et al. 2007). Despite their ecological and commercial importance, key information central to management and conservation, including how populations are main- tained and connected genetically, remains largely unknown. Similar to other sessile marine invertebrates, sponges have a bipartite life cycle during which the extent of dispersal of the larval phase is likely to affect population genetic structure (Hellberg 2007). Whilst our understanding of larval dispersal is best approached with a composite of data, including larval behaviours and hydrodynamics, arguably the most convincing data allowing us to infer levels of larval dispersal come from population genetic studies.

Population genetic data for sponges have routinely focused on allozyme analyses (see review Sole-Cava \& Boury-Esnault 1999), with comparatively fewer studies 
utilising other molecular markers. Both mitochondrial and nuclear ribosomal (i.e. internal transcribed spacers - ITS) DNA markers have been used to assess population genetic structure for sponge species, with most markers exhibiting low levels of variability (Duran et al. 2004a, Worheide 2006). Low variability associated with these markers - for the species examined to dateis potentially a reflection of low rates of evolution associated with these genes (Worheide 2006). In one study (Duran et al. 2004b), microsatellite DNA variation was used to infer population genetic structure. More recently, the use of single-stranded conformation polymorphism (SSCP) of the ATP beta synthetase subunit gene has provided a promising direction for assessing population genetic structure in sponges (Bentlage \& Worheide 2007).

Population genetic patterns for sponges are predominantly associated with genetic subdivision over distances ranging from a few kilometres (Whalan et al. 2005), to 10s and 100s of kilometres (Benzie et al. 1994, Sole Cava \& Boury-Esnault 1999, Duran et al. 2004a,b). Very few sponge species show panmixia over large spatial scales (Lazoski et al. 2001). Our understanding of larval dispersal, as inferred from population genetic structure in sponges, is to a large degree still fragmented. Sponges appear to be a group with restricted larval dispersal capabilities, and there is a clear need to investigate a wider cross section of sponge species that encompass different reproductive traits (e.g. brooders vs. spawners), and larval behaviours, and to quantify the effects these life-strategies may have on formation of population genetic structure.

The present study examined the population genetic structure of the Great Barrier Reef (GBR) sponge
Rhopaloeides odorabile, which is widely distributed on both inner- and mid-shelf reefs (Wilkinson \& Cheshire 1989). $R$. odorabile is a brooding dictyoceratid sponge that 'dribble spawns' well-developed larvae over several weeks of the Austral summer (Whalan et al. 2007). Although these larvae have short pre-settlement competencies and are poor swimmers, their pre-settlement vertical migration behaviour is likely to contribute to dispersal (Whalan 2007). Comprehensive data detailing the reproductive and larval ecology of this species make it an ideal model in assessing and interpreting population genetic patterns in brooding sponges. It is currently unknown if an inter-reefal sector separating inner- and mid-shelf reef sites is a sufficient barrier to disrupt population connectivity between these 2 regions. We used allozyme electrophoretic and mitochondrial DNA (cytochrome oxidase sub-unit 1 gene) data to (a) test the hypothesis that genetic differentiation is exhibited between $R$. odorabile on inner-reef sites and mid-reef sites and (b) determine the patterns of connectivity among reefs separated by distances ranging from 1 to $140 \mathrm{~km}$ throughout the central GBR.

\section{MATERIALS AND METHODS}

Study sites and sample collection. Samples from sponges were collected by SCUBA between August 2003 and September 2004. Collections were obtained from a total of 4 sites within the Palm Island group situated on the inner-shelf region of the central GBR, and from 11 sites on mid-shelf reefs of the central GBR (Fig. 1, Table 1). This enabled broad scale comparisons



Fig. 1. Location map detailing collection sites of Rhopaloeides odorabile samples in relation to the geography of the central Great Barrier Reef. More detailed information on collection sites is located in Table 1 
Table 1. Sampling sites and collection dates for Rhopaloeides odorabile on the central Great Barrier Reef. * Exact co-ordinates could not be collected for these sites due to a GPS malfunction but are estimated to be in the vicinity of 2 to $4 \mathrm{~km}$ from Davies Reef 1

\begin{tabular}{|lccc|}
\hline Site (abbreviation) & Latitude & Longitude & Date \\
\hline Inner-shelf reefs & & & \\
Albino Rock (A) & $18^{\circ} 45.996^{\prime} \mathrm{S}$ & $146^{\circ} 42.871^{\prime} \mathrm{E}$ & Sep 2003 \\
Fantome Island (F) & $18^{\circ} 40.424^{\prime} \mathrm{S}$ & $146^{\circ} 31.639^{\prime} \mathrm{E}$ & Sep 2004 \\
S. Pelorus Island (SP) & $18^{\circ} 31.955^{\prime} \mathrm{S}$ & $146^{\circ} 29.625^{\prime} \mathrm{E}$ & Mar 2004 \\
N. Pelorus Island (NP) & $18^{\circ} 33.624^{\prime} \mathrm{S}$ & $146^{\circ} 29.722^{\prime} \mathrm{E}$ & Sep 2004 \\
Mid-shelf reefs & & & \\
Broadhurst Reef 1 (B1) & $18^{\circ} 52.261^{\prime} \mathrm{S}$ & $147^{\circ} 42.350^{\prime} \mathrm{E}$ & Sep 2003 \\
Broadhurst Reef 2 (B2) & $18^{\circ} 52.908^{\prime} \mathrm{S}$ & $147^{\circ} 42.203^{\prime} \mathrm{E}$ & Jun 2004 \\
Broadhurst Reef 3 (B3) & $18^{\circ} 53.010^{\prime} \mathrm{S}$ & $147^{\circ} 42.071^{\prime} \mathrm{E}$ & Jun 2004 \\
Davies Reef 1 (D1) & $18^{\circ} 49.010^{\prime} \mathrm{S}$ & $147^{\circ} 37.968^{\prime} \mathrm{E}$ & Sep 2003 \\
Davies Reef 2 (D2) & ${ }^{*}$ & & Jun 2004 \\
Davies Reef 3 (D3) & ${ }^{*}$ & ${ }^{*}$ & Jun 2004 \\
Lynch Reef 1 (L1) & $18^{\circ} 44.244^{\prime} \mathrm{S}$ & $147^{\circ} 42.938^{\prime} \mathrm{E}$ & Sep 2003 \\
Lynch Reef 2 (L2) & $18^{\circ} 45.958^{\prime} \mathrm{S}$ & $147^{\circ} 41.232^{\prime} \mathrm{E}$ & Jun 2004 \\
Lynch Reef 3 (L3) & $18^{\circ} 45.670^{\prime} \mathrm{S}$ & $147^{\circ} 41.226^{\prime} \mathrm{E}$ & Jun 2004 \\
Slashers Reef (SL) & $18^{\circ} 29.485^{\prime} \mathrm{S}$ & $147^{\circ} 08.313^{\prime} \mathrm{E}$ & Aug 2003 \\
Myrmidon Reef (M) & $18^{\circ} 16.827^{\prime} \mathrm{S}$ & $147^{\circ} 29.934^{\prime} \mathrm{E}$ & Aug 2003 \\
\hline
\end{tabular}

between inner- and mid-shelf reef regions separated by distances of 10 s of kilometres. Medium- and finescale differences were assessed by examining variation amongst sites within each region, and for reefs within the reef complexes at Davies (D), Broadhurst (B) and Lynch (L) Reefs, which provided comparisons over distances of several kilometres. The habitats that sponges were collected from were similar. Inner-shelf reef sites of the Palm Islands occur on either the reef flat or slope regions of fringing reefs, 5 to $12 \mathrm{~m}$ in depth. Sponges on the mid- and outer-shelf reef sites were collected from back and front reef slopes, 5 to $15 \mathrm{~m}$ in depth.

Sponges were located using SCUBA, and a sharp knife was used to excise samples from each sponge. Samples were placed in liquid nitrogen and, on return to the laboratory, were transferred to $-80^{\circ} \mathrm{C}$ until required for genetic analysis. Geographic distances between sites were determined using the software Ozi Explorer (Version 3.95.4e, D\&L Software) and are based on the shortest straight line distance between sites as determined by their respective GPS coordinates.

Allozyme electrophoresis. We undertook an analysis of allozymes based on the previous success with this method in detecting polymorphic and resolvable enzymes in sponges (Sole Cava \& Boury-Esnault 1999). Allozyme electrophoresis was used to compare the genetic structure of Rhopaloeides odorabile populations within and among 15 sites. To determine which enzyme-encoding loci were polymorphic and therefore would be informative for a population genetic study, a preliminary survey of 34 enzyme systems using dif- ferent electrophoretic buffers was undertaken. Thirtytwo sponges, representing a random selection of individuals from all sample sites, were examined for each enzyme system tested.

Allozymes were assayed on $12 \%$ w/v horizontal starch gels using either Tris-citrate $\mathrm{pH} 8$ (TC8) or TrisEDTA borate (TEB) buffers, as described in Whalan et al. (2005). Out of the 32 enzymes tested, 4 could be reliably scored, although the monomorphic expression at 1 locus (isocitrate dehydrogenase) precluded informative data collection. Following electrophoresis, gels were stained for the polymorphic enzymes phosphoglucose isomerase (PGI; EC 5.3.1.9), malate dehydrogenase $(\mathrm{MDH}$; EC 1.1.1.37) and an unidentified dehydrogenase (now abbreviated as NDH) using an enzyme recipe for xanthine dehydrogenase (EC 1.17.1.4). Alleles were labelled alphabetically according to their relative rates of electrophoretic mobility.

Mitochondrial DNA analysis. Nucleic acids (DNA) were extracted from sponges from 15 sites across the central GBR for amplification of partial sequences of the mitochondrial DNA (mtDNA) cytochrome oxidase sub-unit 1 gene (CO1). DNA was extracted by grinding $100 \mathrm{mg}$ of tissue in $750 \mu \mathrm{l}$ of grinding buffer $(100 \mathrm{mM}$ Tris; $100 \mathrm{mM}$ EDTA; $1 \%$ SDS; $100 \mathrm{mM} \mathrm{NaCl}$; Milli Q $\mathrm{H}_{2} \mathrm{O}$ ) and incubating at $65^{\circ} \mathrm{C}$ for $2 \mathrm{~h}$. Following this, potassium acetate was added to a final concentration of $1 \mathrm{M}$ and the extract was stored on ice for $30 \mathrm{~min}$ before being centrifuged at $16100 \times g$ for $15 \mathrm{~min}$ and the supernatant collected. Nucleic acids were precipitated by adding $0.8 \mathrm{vol}$ of $100 \%$ isopropanol to the supernatant and standing at room temperature for $5 \mathrm{~min}$, followed by centrifugation at $16100 \times g$ for $15 \mathrm{~min}$. Pelleted DNA was washed twice with $70 \%$ ethanol and dried in a heated vacuum centrifuge for $3 \mathrm{~min}$.

The universal primers HCO2198 and LCO1490 (Folmer et al. 1994) were initially tested. However, PCR products using these primers yielded poor sequences. To obtain more informative sequences, PCR products amplified using the Folmer et al. (1994) primers were subsequently cloned into a pGEM-T (Promega) vector following the manufacturer's instructions. PCR reactions using standard vector primers (T7 and SP6) were carried out for 24 colonies, and the products were sequenced by a commercial company (Macrogen). The resulting sequences were then aligned using Sequencher (Version 4.5, GeneCodes Corp) and based on conserved sequence alignments; species-specific primers were designed using the software Oligo (Version 4) (RO-CO1F 5'GGAACGGTGGGTTTATCTTTAAGTTTG3' and RO-CO1R 5'GGAACAATATGGGGTCTCCGCCTC3').

Amplifications were carried out on a Peltier Thermocycler (DNA engine Tetrad 2, MJ Research) in $25 \mu$ l total reaction volumes consisting of $10 \times$ Qiagen buffer with 
$1.5 \mathrm{mM} \mathrm{MgCl}_{2}, 0.2 \mu \mathrm{M}$ of each forward and reverse

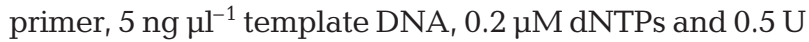
of Taq polymerase (Qiagen). Amplifications were performed at the following cycling temperature regime; an initial denaturation of $94^{\circ} \mathrm{C}$ for 2 min; 35 cycles at $94^{\circ} \mathrm{C}$ for $30 \mathrm{~s}, 50^{\circ} \mathrm{C}$ for $30 \mathrm{~s}, 72^{\circ} \mathrm{C}$ for $45 \mathrm{~s}$, and a final extension of $72^{\circ} \mathrm{C}$ for $5 \mathrm{~min}$. This protocol yielded strong amplification products allowing direct sequencing of Sephadexpurified PCR products. Sequencing of PCR products on both forward and reverse sequences were carried out by Macrogen Incorporated. Sequences were aligned and edited using the software Sequencher (Version 4.5, GeneCodes Corp.), providing a final sequence length of $528 \mathrm{bp}$ for analysis. Sequence data have been deposited in the GenBank database under accession numbers (EU 64446 to EU 64448).

Data analysis. Departures from Hardy-Weinberg equilibrium (HWE) were determined for each allozyme locus using $F_{\text {IS }}$ (Weir \& Cockerham 1984), with significance of departures from HWE being determined by Exact tests (Raymond \& Rousset 1995), as calculated in GENEPOP (http://genepop.curtin.edu.au/).

To test the hypothesis that population genetic structure occurs in Rhopaloeides odorabile between sites on the inner- and mid-shelf reefs, we used 2 analytical procedures. (1) We determined pairwise $F_{\mathrm{ST}}$ values between each site using Arlequin (Version 3.01; Excoffier et al. 2005). Non-metric multidimensional scaling (MDS) using pairwise $F_{\mathrm{ST}}$ values was performed to determine groupings of sites based on genetic similarity and to provide a graphical picture of the spatial patterns associated with genetic structure. This spatial pattern was then compared to that expected if gene flow between sites was primarily restricted within localised reef, or reef systems. To aid in the interpretation of differences among sites in the MDS, the methods of Johnson et al. (2001) were followed. This procedure provides a scale of significance within the MDS plot that is a useful approximation for detecting differences between sites. (2) To specifically test for genetic structure between our arbitrary groupings of inner- and mid-reef sites, we undertook a hierarchical analysis of genetic structure using analysis of molecular variance (AMOVA; Arlequin Version 3.01).

\section{RESULTS}

\section{Genetic diversity}

\section{Allozymes}

PGI was highly variable showing 6 alleles. MDH was less variable, exhibiting 2 alleles. The remaining nonspecific locus was not identified, but contained 2 alle- les, and most likely represented an unknown dehydrogenase (Richardson et al. 1986). This type of non-specific dehydrogenase activity has been reported for other sponges (Boury-Esnault et al. 1999, Lazoski et al. 2001). Because the positions where alleles separated on the starch gels were distinctly different to the other 2 loci (i.e. PGI and MDH), it was included in the analyses in the present study.

Alleles for all 3 loci were consistently found in all populations, with only minor differences in allele frequencies present between sites. No alleles were found with a frequency $>0.85$ (Table 2). Significant departures from HWE were present across all 3 loci for South Pelorus. A further 8 sites exhibited significant single locus HWE departures, with most occurring at the PGI locus (Table 2).

\section{mtDNA}

A partial sequence, 528 bp in length, was amplified from the CO1 gene from 212 sponges on the central GBR. Three positional changes, representing 3 different CO1 haplotypes were found. Haplotype 1 was the most dominant haplotype (range 55 to $100 \%$ ) and was common to all sites, whilst Haplotype 2 was found at the majority of sites at varying frequencies (range 4 to $40 \%$ ). Haplotype 3 was found at lower frequencies (range 4 to $28 \%$ ) and at only 6 out of the 15 sites (Table 2).

\section{Population genetic structure}

\section{Allozymes}

Based on the AMOVA, our hypothesis that there is differentiation between Rhopaloeides odorabile on inner- and mid-shelf sites was not supported. There was no significant differentiation between these 2 regions, and $<1 \%$ of the variation was explained by the spatial arrangement of the sampling sites. Most of the variation (98\%) was within populations (Table 3).

Comparisons of pairwise $F_{\mathrm{ST}}$ values for reef sites (i.e. bommies) within the reef complexes of Davies, Lynch and Broadhurst indicated that there was no small-scale (significant) genetic differentiation between several of these sites (Table 4). Consequently, sites within these reef complexes that showed no significant genetic differentiation were pooled (i.e. D2 + D3 and B2 + B3).

Out of the 78 pairwise distinct reef site comparisons, 52 showed significant genetic differentiation (raw data). Following Bonferroni corrections, the number of significant pairwise comparisons decreased to 24 . Notably, 4 sites (L2, L3, B2/3 and D2/3) were geneti- 
Table 2. Rhopaloeides odorabile. Allele frequencies at 3 allozyme loci and haplotype frequencies at the mtDNA cytochrome oxidase sub-unit 1 gene from 15 sites on the central Great Barrier Reef. Letters A-F in first column: allozyme loci alleles. n: numbers of $R$. odorabile individuals sampled at each site; $F_{\mathrm{IS}}$ : inbreeding of individuals relative to their sub-population, with negative values indicative of heterozygote deficits and bold values significant at $\mathrm{p}<0.05$; PGI: phosphoglucose isomerase; MDH: malate dehydrogenase; NDH: unidentified enzyme activity; H1, H2 and H3: Haplotypes 1, 2, and 3, respectively. Site abbreviations in Table 1

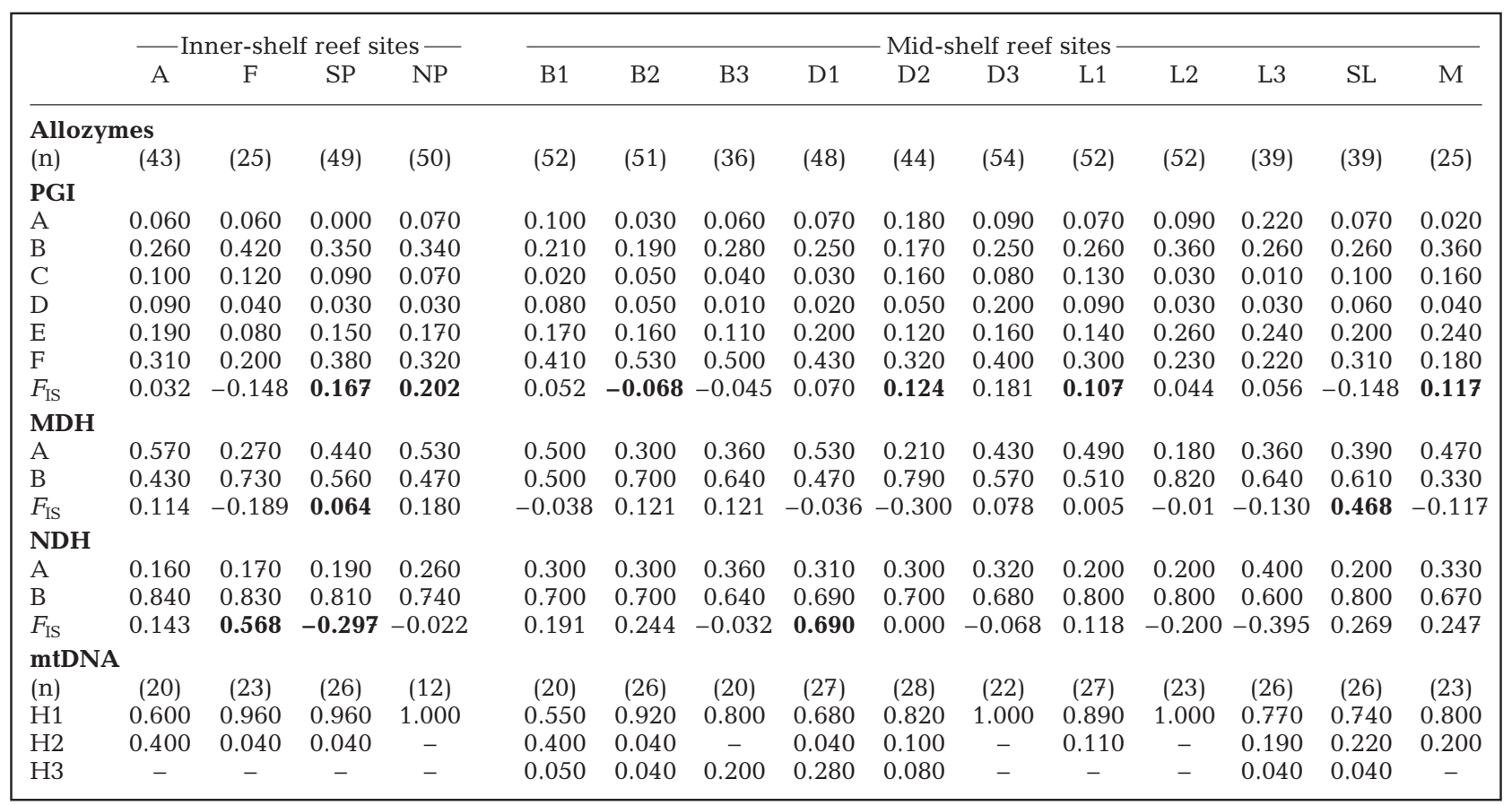

cally differentiated in most of their pairwise site comparisons (Table 4). While there were no clear groupings of sites according to the MDS ordination, the positions of L2, L3, B2/3 and D2/3 on the periphery of the ordination explained a large component of the heterogeneity (Fig. 2).

\section{mtDNA}

Similar to the allozyme results, AMOVA analysis of mtDNA data showed no significant differentiation between Rhopaloeides odorabile on inner- and midshelf reef sites. Less than $1 \%$ of the variation was explained between sponges on inner- versus mid-shelf reefs, with $89 \%$ of the variation attributed within populations (Table 3).

On a between-population comparison basis, pairwise $F_{\mathrm{ST}}$ revealed no significant differences between several sites within their respective reef complexes of Davies, Lynch and Broadhurst (D2 + D3; L1 + L2; B1 + B3). Consequently, these sites were pooled before undertaking further analyses. Pairwise $F_{\text {ST }}$ comparisons showed 28 out of the 66 pairwise comparisons to be significant (raw data), although following Bonferroni corrections only 2 pairwise comparisons remained significant. Levels of heterogeneity appear to be driven by 3 notable sites-
D1, Myrmidon and Albino- each of which recorded significant pairwise $F_{\mathrm{ST}}$ values for more than half of their pairwise site comparisons (Table 5). These patterns are also shown clearly in the MDS ordination, with Albino and Myrmidon clustering as 1 group on the periphery of the MDS and with clear separation from all other sites (Fig. 3). Whilst D1 is associated with other mid-shelf reef sites (i.e. B1/3, L3 \& Slashers Reef), which are identified as a group in the ordination, its separation from other sites within this group also highlighted its determining

Table 3. Rhopaloeides odorabile. AMOVA for mtDNA data showing levels of genetic structuring ( $F$ statistics), and variation (\%) attributable to each spatial scale analysed. Groups were determined from exploratory AMOVA and multidimensional scaling of pairwise $F_{\mathrm{ST}}$ to detect obvious groupings within the MDS ordination. F: fixation index, significant at ${ }^{*} \mathrm{p}<0.01$ using 10000 permutations

\begin{tabular}{|llc|}
\hline Spatial comparison & $F$ & Variation (\%) \\
\hline mtDNA & & \\
Between inner- and mid-reef sites & 0.007 & 0.730 \\
Among sites (within reef groups) & $0.100^{*}$ & 9.950 \\
Within reefs & $0.110^{*}$ & 89.310 \\
Allozymes & & \\
Between inner- and mid-reef sites & 0.001 & 0.060 \\
Among sites (within reef groups) & $0.010^{*}$ & 1.420 \\
Within reefs & $0.010^{*}$ & 98.520 \\
\hline
\end{tabular}


Table 4. Rhopaloeides odorabile. Matrix of pairwise $F_{\mathrm{ST}}$ in 3 allozyme loci among 12 sites on the central Great Barrier Reef. Significant values of $F_{\mathrm{ST}}$ are indicated in italics (raw values) and after Bonferroni corrections in bold italics $\left({ }^{*} \mathrm{p}<0.05 ;{ }^{* *} \mathrm{p}<0.01\right)$. Site abbreviations in Table 1

\begin{tabular}{|c|c|c|c|c|c|c|c|c|c|c|c|c|}
\hline & A & F & SP & $\mathrm{NP}$ & B1 & B2/3 & D1 & $\mathrm{D} 2 / 3$ & L1 & L2 & L3 & SL \\
\hline F & $0.001^{*}$ & & & & & & & & & & & \\
\hline SP & $0.012^{* *}$ & 0.002 & & & & & & & & & & \\
\hline NP & $0.007^{*}$ & 0.006 & $0.004^{*}$ & & & & & & & & & \\
\hline B1 & 0.002 & 0.006 & 0.004 & $0.005^{*}$ & & & & & & & & \\
\hline B $2 / 3$ & $0.046^{* *}$ & 0.023 & $0.026^{* *}$ & $0.024^{* *}$ & $0.025^{* *}$ & & & & & & & \\
\hline D1 & $0.009^{*}$ & 0.005 & 0.003 & $0.006^{*}$ & 0.001 & $0.025^{* *}$ & & & & & & \\
\hline $\mathrm{D} 2 / 3$ & $0.023^{* *}$ & 0.006 & $0.005^{*}$ & $0.013^{* *}$ & $0.009^{* *}$ & $0.008^{* *}$ & $0.007^{* *}$ & & & & & \\
\hline L1 & $0.007^{*}$ & 0.003 & 0.004 & 0.002 & 0.003 & $0.016^{* *}$ & $0.005^{*}$ & 0.004 & & & & \\
\hline L2 & $0.010^{* *}$ & 0.008 & $0.015^{* *}$ & $0.010^{* *}$ & $0.010^{* *}$ & $0.039^{* *}$ & $0.017^{* *}$ & $0.021^{* *}$ & $0.016^{* *}$ & & & \\
\hline L3 & $0.015^{* *}$ & $0.015^{* *}$ & $0.014^{* *}$ & $0.008^{* *}$ & $0.021^{* *}$ & $0.043^{* *}$ & $0.016^{* *}$ & $0.017^{* *}$ & $0.014^{* *}$ & $0.016^{* *}$ & & \\
\hline SL & 0.003 & 0.007 & $0.008^{*}$ & 0.005 & 0.003 & $0.032^{* *}$ & $0.009^{* *}$ & $0.130^{* *}$ & $0.003^{*}$ & $0.012^{* *}$ & $0.012^{* *}$ & \\
\hline M & $0.010^{* *}$ & 0.004 & $0.006^{*}$ & $0.012^{* *}$ & $0.090^{* *}$ & $0.052^{* *}$ & $0.011^{* *}$ & $0.190^{* *}$ & $0.013^{*}$ & $0.011^{* *}$ & $0.007^{*}$ & $0.007^{*}$ \\
\hline
\end{tabular}

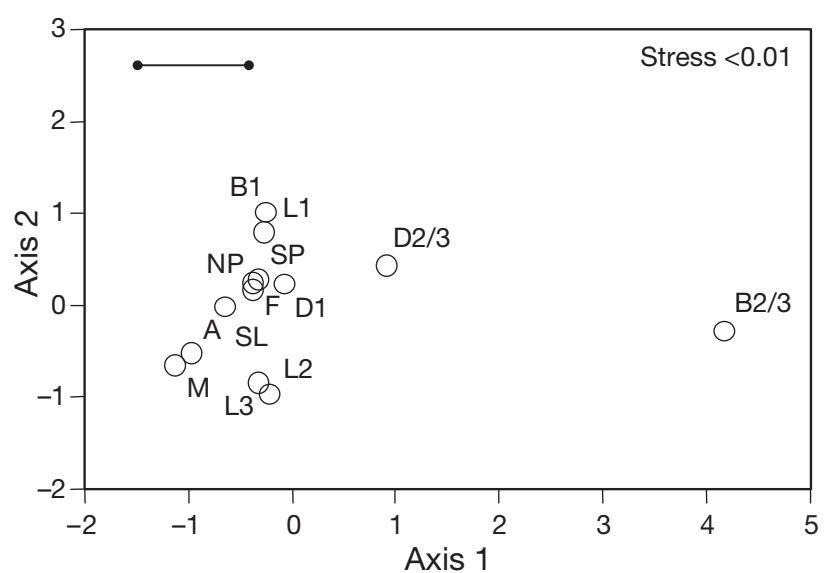

Fig. 2. Rhopaloeides odorabile. Multidimensional scaling of pairwise $F_{\mathrm{ST}}$ (allozymes) among 13 sites of the central Great Barrier Reef. Scale bar: an approximate measure within MDS space in which pairwise $F_{\mathrm{ST}}$ is significant. Note the pooling of sites within Broadhurst Reef (B2/3: B2 + B3) and Davies Reef (D2/3: D2 + D3) following an initial analysis in which these sites were not significantly differentiated. Site abbreviations in Table 1 power in explaining levels of differentiation. Overall, grouping of sites in the ordination appears chaotic, with inner-shelf reef sites grouping with mid-shelf reef sites, suggesting a poor relationship with spatial locality and genetic connectivity. Closely aligned mid-shelf reef sites are differentiated, whilst other mid-shelf reef sites showed homogeneity with inner-shelf reef sites, although separated by 10 s of kilometres. For example, B2 is within the same reef complex as B1 + B3 and, although separated by just $1.1 \mathrm{~km}$, it showed significant genetic differentiation. However, B1 + B3 exhibited genetic connection to other inner- and mid-shelf reefs despite being separated by 10 s of kilometres.

\section{DISCUSSION}

Results from allozyme and mtDNA CO1 data support the existence of low levels of genetic differentiation at both the broadest (i.e. $10 \mathrm{~s} \mathrm{~km}$ ) and smallest reef spatial scales $(1 \mathrm{~km})$ examined in this study. However, no con-

Table 5. Rhopaloeides odorabile. Matrix of pairwise $F_{\mathrm{ST}}$ values following analysis of mtDNA (CO1) for sponges collected from the central Great Barrier Reef. Significant values of $F_{\mathrm{ST}}$ are indicated in italics (raw values) and after Bonferroni corrections in bold italics $(\mathrm{p}<0.01)$. Site abbreviations in Table 1

\begin{tabular}{|c|c|c|c|c|c|c|c|c|c|c|c|}
\hline & A & F & SP & NP & B13 & B2 & D1 & D23 & L12 & L3 & SL \\
\hline F & 0.289 & & & & & & & & & & \\
\hline SP & 0.313 & -0.042 & & & & & & & & & \\
\hline NP & 0.302 & -0.138 & -0.034 & & & & & & & & \\
\hline B13 & 0.023 & 0.119 & 0.132 & 0.132 & & & & & & & \\
\hline B2 & 0.256 & -0.031 & -0.026 & -0.019 & 0.089 & & & & & & \\
\hline D1 & 0.148 & 0.184 & 0.199 & 0.179 & 0.017 & 0.130 & & & & & \\
\hline D23 & 0.253 & -0.016 & -0.009 & -0.002 & 0.087 & -0.027 & 0.136 & & & & \\
\hline $\mathrm{L} 12$ & 0.357 & -0.004 & -0.007 & 0.011 & 0.142 & -0.022 & 0.169 & -0.003 & & & \\
\hline L3 & 0.038 & 0.073 & 0.088 & 0.099 & -0.014 & 0.048 & 0.061 & 0.037 & 0.109 & & \\
\hline SL & 0.014 & 0.099 & 0.115 & 0.124 & 0.018 & 0.074 & 0.065 & 0.064 & 0.141 & -0.037 & \\
\hline $\mathrm{M}$ & 0.049 & 0.271 & 0.292 & 0.285 & 0.022 & 0.242 & 0.146 & 0.238 & 0.338 & 0.034 & 0.012 \\
\hline
\end{tabular}




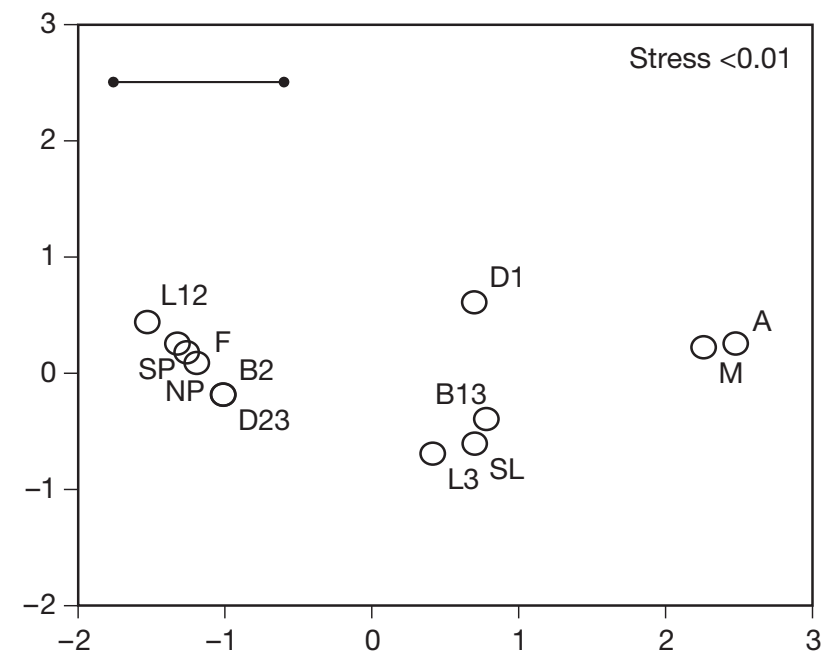

Fig. 3. Rhopaloeides odorabile. Multidimensional scaling of pairwise $F_{\mathrm{ST}}$ (mtDNA) among 12 collection sites from the central Great Barrier Reef. Scale bar: an approximate measure within MDS space in which $F_{\mathrm{ST}}$ is significant. Note the pooling of sites within Lynch Reef (L1/2: L1 and L2), Broadhurst Reef (B1/3: B1 and B3) and Davies Reef (D2/3: D2 and D3) following an initial analysis in which these sites were not significantly differentiated. Site abbreviations in Table 1

sistent patterns of genetic connectivity in relation to spatial sampling across the reef platform were observed, with pairwise comparisons among sampled reefs showing an overall pattern of genetic patchiness. Moreover, our hypothesis that genetic structure would occur between inner- and mid-reef sites could not be supported with our data, suggesting that the interreefal region separating the shelf reefs does not significantly impede genetic connectivity.

Despite the absence of strong genetic structure in Rhopaloeides odorabile between inner- and mid-shelf reef systems, there was also evidence for restriction of gene flow among sponge populations. The low levels of polymorphism in $R$. odorabile observed in the 3 allozyme loci and mtDNA CO1 gene require some caution in terms of the overall interpretation. Nevertheless, the detection of differences between many of the sites for both markers, coupled with the overall pattern of genetic patchiness, indicates that restrictions to gene flow among some reefs are present, not necessarily as a consequence of spatial arrangement, but due to other factors such as dispersal and inter-reef circulation patterns at the time the larvae are released. This is most evident from comparisons in haplotype frequencies between the Albino Rock and Fantome Island populations, and the B1 and B2 sites, where quite dramatic shifts were seen in haplotype frequencies despite the fact that the sites are geographically proximate.
Dispersal ability in marine invertebrates has been related to planktonic competency periods, with lecithotrophic larvae spending less time in the plankton and therefore having a reduced potential for dispersal than planktotrophic larvae (Hellberg 1996, Ayre \& Hughes 2000). Rhopaloeides odorabile is a brooding sponge species (Whalan et al. 2007) and shows genetic homogeneity between sites separated by 10 s of kilometres. This contrasts with a previous allozyme study of sponge population genetics on the GBR, where several brooding dictyoceratid sponges exhibited genetic differentiation among sites separated by 10 s to $100 \mathrm{~s}$ of kilometres (Benzie et al. 1994). To our knowledge there is nothing known of the larval pre-competency periods or dispersal ability for larvae of these sponges. Benzie et al. (1994) also found that genetic divergence, for each of the 4 sponge populations, increased with increasing geographical separation, which clearly contrasts with the genetic patchiness observed in $R$. odorabile populations. The apparent homogeneity between populations of $R$. odorabile separated by 10 s of kilometres suggests the brooded larvae of this sponge are capable of dispersing beyond natal reefs. Nevertheless, fine-scale heterogeneity over distances as small as $1 \mathrm{~km}$ (e.g. sites within Broadhurst Reef) also indicates endogenous recruitment. The apparent lack of relationship between geographical separation and genetic structure suggests these patterns may best be interpreted as larvae being dispersed in different directions and over different distances depending on the prevailing circulation.

Rhopaloeides odorabile larvae have pre-competency periods of up to $54 \mathrm{~h}$ and exhibit vertical migration behaviours (Whalan 2007), which provide a mechanism for passive dispersal via wind-driven surface currents. Hydrodynamics can restrict larvae to natal reefs and limit the exchange of water carrying larvae from more distant reefs; however, the ephemeral nature of currents can also contribute to complex circulation patterns, leading to variable patterns of retentionor, indeed, advection-depending on reef size, shape, aspect (leeward or windward side) and time (Black et al. 1991, Legrand et al. 2006). $R$. odorabile females release larvae daily over several weeks and therefore presumably under different tidal and current regimes (Whalan 2007). The genetic patchiness of $R$. odorabile is likely to be linked to larval dispersal that is subject to complicated reef-specific hydrodynamics at the time of larval release, and this interpretation would explain the genetic patchiness observed in this species.

Although both allozyme and mtDNA (CO1) data for Rhopaloeides odorabile supported an overall similar genetic pattern of low levels of localised subdivision and connectivity between distant sites, the levels of variation were lower (although still significant) for 
allozyme data. Mitochondrial DNA data, however, revealed more obvious patterns of differentiation. Similar disparities of genetic structure are reported for other marine invertebrates using multiple markers (Mitton 1994 and references within), and these discordant patterns have been explained in terms of historical patterns of gene flow rather than contemporary events.

Historical events associated with sea level fluctuations are thought to have exposed populations to different current regimes, isolation of populations and patterns of gene flow (Benzie 1999, Worheide et al. 2002, Smith-Keune \& van Oppen 2006). Present day GBR sea levels are markedly higher than those during the last glaciation event ca. 18000 yr ago, with recolonisation of the present reef communities occurring from ca. 10000 yr ago, when sea levels commenced their rise to their present level ca. 6000 yr ago (Carter \& Johnson 1986). Present genetic patterns, therefore, may be far from equilibrium with respect to migration and genetic drift and, rather than reflecting levels of current gene flow (or larval dispersal strategies), represent historical footprints (Benzie 1999) where gene flow was more open among reef populations. Despite our conclusions that larval dispersal behaviours support the formation of low levels of genetic structure for $R$. odorabile, the effect of past genetic signatures still influencing current observed patterns of genetic structure cannot be overlooked.

Finally, the low levels of mtDNA (CO1) variability associated with the samples in this study are consistent with the findings of other studies investigating this same gene region for both sponge and coral species (Shearer et al. 2002, Duran et al. 2004a, Worheide 2006). The low rates of variability for sponges and cnidarians have been interpreted in terms of their low rates of evolution in association with long generation times and low metabolic rates (Worheide 2006). Why these groups display such slow rates of evolution is an intriguing question. It is becoming clear that the utility of the mitochondrial CO1 gene to address population genetic questions in sponges is limited, and the focus should be on more informative markers such as the ATP beta synthetase subunit gene (Bentlage \& Worheide 2007).

Acknowledgements. This project was part of the sponge aquaculture programme of AIMS@JCU, which receives funding and in-kind support from the Australian Institute of Marine Science, James Cook University Research Advancement Programme (Finfish and Emerging Aquaculture), Great Barrier Reef Research Foundation, Coolgaree Aboriginal Corporation, Queensland Department of State Development Innovation and Trade, Queensland Department of Primary Industries and Fisheries, and the Commonwealth Department of Transport and Regional Services. C. Wolff, E. Evans-Illidge,
R. Bannister and P. Ettinger-Epstein assisted with collections and B. Ballment with allozymes. The location map detailing collection sites was provided by T. Stieglitz.

\section{LITERATURE CITED}

Ayre DJ, Hughes TP (2000) Genotypic diversity and gene flow in brooding and spawning corals along the Great Barrier Reef, Australia. Evolution 54:1590-1605

> Bentlage B, Worheide G (2007) Low genetic structuring among Pericharax heteroraphis (Porifera: Calcarea) populations from the Great Barrier Reef (Australia), revealed by analysis of nrDNA and nuclear intron sequences. Coral Reefs 26:807-816

Benzie JAH (1999) Genetic structure of coral reef organisms: ghosts of dispersal past. Am Zool 39:131-145

> Benzie JAH, Sandusky C, Wilkinson CR (1994) Genetic structure of dictyoceratid sponge populations on the western Coral Sea reefs. Mar Biol 119:335-345

Black KP, Moran PJ, Hammond LS (1991) Numerical models show coral reefs can be self seeding. Mar Ecol Prog Ser 74:1-11

Boury-Esnault N, Klautau M, Bezac C, Wulff J, Sole-Cava AM (1999) Comparative study of putative conspecific sponge populations from both sides of the Isthmus of Panama. J Mar Biol Assoc UK 79:39-50

Carter RM, Johnson DP (1986) Sea level controls on the post glacial development of the Great Barrier Reef, Queensland. Mar Geol 71:137-164

> Duran S, Pascual M, Turon X (2004a) Low levels of genetic variation in mtDNA sequences over the western Mediterranean and Atlantic range of the sponge Crambe crambe. (Poecilosclerida). Mar Biol 144:31-35

> Duran S, Pascual M, Estoup A, Turon X (2004b) Strong population structure in the marine sponge Crambe crambe (Poeilosclerida) as revealed by microsatellite markers. Mol Ecol 13:511-522

Excoffier L, Laval G, Schneider S (2005) Arlequin Ver. 3. 0. An integrated software package for population genetics data analysis. Evol Bioinform Online 1:47-50

Folmer O, Black M, Hoech W, Lutz R, Vrijenhoeck R (1994) DNA primers for amplification of mitochondrial cytochrome $c$ oxidase subunit 1 from diverse metazoan invertebrates. Mol Mar Biol Biotechnol 3:294-299

> Fromont J, Vanderklift MA, Kendrick GA (2006) Marine sponges of the Dampier Archipelago, Western Australia: patterns of species distribution, abundance and diversity. Biodivers Conserv 15:3731-3750

Hellberg ME (1996) Dependence of gene flow on geographic distance in two solitary corals with different larval dispersal capabilities. Evolution 50:1167-1175

Hellberg ME (2007) Footprints on the water: the genetic wake of dispersal among reefs. Coral Reefs 26:463-473

> Johnson MS, Bentley SL, Ford SS, Ladyman MT, Lambert GJ (2001) Effects of a complex archipelago on genetic subdivision of the intertidal limpet Siphonaria kurracheensis. Mar Biol 139:1087-1094

> Kowalke J (2000) Ecology and energetics of two Antarctic sponges. J Exp Mar Biol Ecol 247:85-97

> Lazoski C, Sole-Cava AM, Boury-Esnault N, Klautau M, Russo CA (2001) Cryptic speciation in a high gene flow scenario in the oviparous marine sponge Chondrosia reniformis. Mar Biol 139:421-429

> Legrand S, Deleersnijder E, Hanert E, Legat V, Wolanski E (2006) High resolution, unstructured meshes for hydrodynamic models of the Great Barrier Reef, Australia. Estuar 
Coast Shelf Sci 68:36-46

Louden D, Whalan S, Evans-Illidge E, Wolff C, de Nys R (2007) An assessment of the aquaculture potential of the tropical sponge Rhopaloeides odorabile and Coscinoderma sp. Aquaculture 270:57-67

Manconi R, Pronzato R (2008) Global diversity of sponges (Porifera: Spongillina) in freshwater. Hydrobiologia 595:27-37

Mitton JB (1994) Molecular approaches to population biology. Annu Rev Ecol Syst 25:45-69

Raymond M, Rousset F (1995) GENEPOP (Version 1.2): populations genetics software for exact tests and ecumenicism. J Hered 86:248-249

Richardson BJ, Baverstock PR, Adams M (1986) Allozyme electrophoresis: a handbook for animal systematics and population studies. Academic Press, Sydney

Schlacher TA, Schlacher-Hoenlinger MA, Williams A, Althaus F, Hooper JNA, Kloser R (2007) Richness and distribution of sponge megabenthos in continental margin canyons off southeastern Australia. Mar Ecol Prog Ser 340: $73-88$

Shearer TL, Van Oppen MJH, Romano SL, Worheide G (2002) Slow mitochondrial DNA sequence evolution in the Anthozoa (Cnidaria). Mol Ecol 11:2475-2487

Sipkema D, Franssen MCR, Osinga R, Tramper J, Wijffels RH (2005) Marine sponges as pharmacy. Mar Biotechnol 7: $142-162$

Smith-Keune C, van Oppen M (2006) Genetic structure of a reef building coral from thermally distinct environments on the Great Barrier Reef. Coral Reefs 25:493-502

Editorial responsibility: Judith Grassle, New Brunswick, New Jersey, USA
Sole-Cava AM, Boury-Esnault N (1999) Patterns of intra- and interspecific divergence in marine sponges. Mem Qld Mus 44:591-602

Weir BS, Cockerham CC (1984) Estimating F-statistics for the analysis of population structure. Evolution 38:1358-1370

Whalan S (2007) Reproduction, larval dispersal and population genetics of the sponge Rhopaloeides odorabile. $\mathrm{PhD}$ thesis, James Cook University, Townsville

> Whalan S, Johnson MS, Harvey E, Battershill C (2005) Mode of reproduction, recruitment, and genetic subdivision in the brooding sponge Haliclona sp. Mar Biol 146:425-433

Whalan S, Battershill C, de Nys R (2007) Sexual reproduction of the brooding sponge Rhopaloeides odorabile. Coral Reefs 26:655-663

Wilkinson CR, Cheshire AC (1989) Patterns in distributions of sponge populations across the central Great Barrier Reef. Coral Reefs 8:127-134

> Worheide G (2006) Low variation in partial cytochrome oxidase subunit 1 (CO1) mitochondrial sequences in the coralline demosponge Astrosclera willeyana across the Indo-Pacific. Mar Biol 148:907-912

Worheide G, Hooper JNA, Degnan BM (2002) Phylogeography of western Pacific Leucetta chagonensis (Porifera: Calcarea) form ribosomal DNA sequences: implications for population history and conservation in the Great Barrier Reef World Heritage Area (Australia). Mol Ecol 11: $1753-1768$

Wulff J (2001) Assessing and monitoring coral reef sponge: Why and how? Bull Mar Sci 69:831-846

Submitted: November 20, 2007; Accepted: May 22, 2008

Proofs received from author(s): July 11, 2008 